\title{
STUDI VARIASI MORFOLOGI TANAMAN TOMAT GUNUNG (Lycopersicum esculentum Mill. var. cerasiforme) DI BANDAR LAMPUNG
}

\begin{abstract}
MORPHOLOGICAL VARIATION STUDY OF CHERRY TOMATO PLANT (Lycopersicum esculentum Mill. var. cerasiforme) IN BANDAR LAMPUNG
\end{abstract}

\author{
Fatimah Fitriyati ${ }^{1}$, Ellyzarti ${ }^{1}$, Martha Lulus Lande ${ }^{1}$ \\ 1 Jurusan Biologi FMIPA Universitas Lampung \\ Email: fatimah_46@ymail.com \\ Jurusan Biologi FMIPA Universitas Lampung \\ Jl. Soemantri Brojonegoro No.1, Bandar Lampung, Lampung, Indonesia, 35145
}

\begin{abstract}
Abstrak
Tomat gunung merupakan tomat pertama yang didomestikasi yang berasal dari Peru dan Chili. Varietas tomat ini memiliki tekstur yang berair, ketika matang berwarna merah menyerupai buah ceri dan berukuran kecil dengan diameter sekitar $1,5 \mathrm{~cm}$. Tujuan penelitian ini adalah untuk mengetahui variasi morfologi tanaman tomat gunung. Penelitian ini telah dilaksanakan dari bulan Mei sampai Agustus 2013. Tahap pertama adalah pengumpulan sampel buah tomat gunung di pasar yang ada di Bandar Lampung. Tahap kedua adalah penanaman biji tomat selama 3 bulan dan pengamatan morfologi batang, daun, bunga dan buah, pada saat tanaman berumur 3 minggu hingga berbuah. Data yang diperoleh dianalisis secara deskriptif dan disajikan dalam bentuk tabel dan foto. Dari hasil pengamatan yang telah dilakukan, diperoleh morfologi batang bulat, beruas-ruas dengan permukaan yang kasar serta berbulu. Batang memiliki banyak cabang dan berwarna hijau kecoklatan. Daun tomat gunung tersusun majemuk menyirip dengan anak daun ganjil, berwarna hijau tua, permukaannya kasar dan berbulu, tepinya dengan toreh berlekuk dan bentuk daun memanjang, ujung daunnya runcing dan pangkal daunnya tumpul. Bunga tersusun majemuk, berbentuk bintang, zigomorf, mahkota berwarna kuning, dan kelopak berwarna hijau tua. Terdapat tiga tipe variasi buah tomat, yaitu bulat, bulat lonjong, dan bulat pipih.
\end{abstract}

Kata kunci: Morfologi, Varietas, Tomat Gunung

\begin{abstract}
Cherry tomato is originally native from Peru and Chile. The Characteristics of cherry tomato fruits are juicy, similar to cherry, with red color at maturation and more than $1,5 \mathrm{~cm}$ in diameter. The purpose of the research was to determine the variation of cherry tomato plant morphology. The research was conducted from May to August 2013. The first step was collecting the sample of cherry tomato fruits in the markets around Bandar Lampung. The second step was planting tomato seeds for 3 months and observing morphology of stems, leaves, flowers and fruits, since the age of 3 weeks until producing fruits. Data were analyzed descriptively and presented in tables and photographs. Based on the research finding, morphology of cherry tomato stem is round, segmented with rough and hairy surface. It has many branches and brownish green color. The leaves are arranged in pinnately compound with odd pinnate, dark green color, rough and hairy surface with serrated margin and elongated shape, tip of the leaves are pointed and its base are blunt. The flowers are arranged in compound, star-shaped, zygomorf, bright yellow petals, and dark green sepals. There are three types of tomato fruit variation that is round, high round, and slightly flattened.
\end{abstract}

Keywords: Morphology, Variety, Cherry Tomato

\section{PENDAHULUAN}

Indonesia memiliki tingkat keanekaragaman hayati yang tinggi dikarenakan Indonesia merupakan negara tropis dengan tingkat curah hujan yang tinggi. Menurut Suryana (2009), diperkirakan sekitar $17 \%$ keanekaragaman hayati dunia berada di Indonesia. Bahkan Indonesia merupakan salah satu dari delapan pusat kea- nekaragaman genetika tanaman di dunia khususnya untuk buah-buahan tropis (Sastrapradja dan Rifai 1989). Salah satu jenis tanaman yang memiliki keanekaragaman varietas adalah tomat.

Menurut Smartt dan Simmonds (1995), diduga tomat gunung merupakan salah satu sumber plasma nutfah tomat. Tomat gunung merupa- 
kan tomat yang pertama kali didomestikasi berasal dari Peru dan Chili. Stertz, et al., (2005) menjelaskan bahwa varietas tomat ini memiliki buah berukuran kecil dengan diameter berkisar $1,5 \mathrm{~cm}$. Buah tomat gunung ini, memiliki tekstur yang berair dan menyerupai buah ceri. Karakteristik buah ini terdapat pada rasanya yang manis dan aromanya yang kuat. Tingkat kebutuhan masyarakat terhadap tomat cukup tinggi. Namun penelitian dan informasi yang menjelaskan tentang keanekaragaman dan variasi morfologi tanaman dari varietas ini sebagai sumber plasma nutfah tomat secara spesifik masih sangat kurang.

\section{BAHAN dan METODE}

Penelitian ini telah dilaksanakan pada bulan Juni sampai bulan Agustus 2013. Penanaman dan pengamatan morfologi tomat gunung dilakukan di Laboratorium Botani Jurusan Biologi FMIPA Universitas Lampung.

\section{Cara Kerja \\ 1. Perkecambahan Bibit Tomat}

Buah tomat gunung diperoleh dari pasar tradisional di Bandar Lampung. Biji tomat dipisahkan dari daging buah dan cairan buahnya lalu dicuci hingga bersih, kemudian dikeringkan di bawah sinar matahari.

Media semai dan media tanam dibuat dari campuran tanah dan pupuk kandang (2:1) dalam 50 polibag ukuran $5 \mathrm{~kg}$.

Benih tomat yang telah dipersiapkan ditabur pada media semai. Media semai dijaga kelembabannya, apabila ada gulma yang tumbuh dibersihkan.

\section{a. Pemindahan Bibit pada Media Tanam dan Pemeliharaan}

Bibit yang telah memiliki 3-4 daun dengan batang yang cukup kokoh kemudian dipindahkan pada media tanam. Media tanam dijaga kelembabannya, demikian juga apabila ada gulma yang tumbuh harus dibersihkan. Saat bibit tomat berumur satu bulan, diberi turus untuk menopang tubuh tanaman.

\section{b. Pengamatan Morfologi}

Pengamatan dan pengukuran morfologi tanaman tomat gunung ini dilakukan pada 10 sampel tanaman tomat yang dipilih secara acak dari 50 tanaman. Pengamatan dan pengukuran ini meliputi:

b1.Morfologi batang yang diamati meliputi bentuk batang, diameter batang, warna batang, jumlah cabang, tinggi maksimal batang dan bulu-bulu halus yang tumbuh di permukaan batang. Pengukuran diameter batang meng- gunakan jangka sorong dan tinggi batang menggunakan meteran.

b2.Morfologi daun yang diamati meliputi warna daun, permukaan daun, tepi daun, bentuk daun dan jumlah daun. Pengukuran panjang dan lebar daun menggunakan penggaris.

b3.Morfologi bunga yang diamati meliputi jumlah maksimal bunga, bentuk dan warna bunga, jumlah mahkota, jumlah kelopak, jumlah putik, jumlah benang sari. Pengukuran panjang mahkota, panjang kelopak, lebar mahkota, lebar kelopak, panjang putik, panjang benang sari menggunakan penggaris.

b4.Morfologi buah yang diamati meliputi warna buah, bentuk buah, diameter buah, jumlah buah, berat buah dan ruang pada buah. Pengukuran diameter buah dilakukan menggunakan jangka sorong dan pengukuran berat buah menggunakan neraca.

\section{c. Analisis Data}

Data variasi morfologi yang diperoleh dari hasil pengamatan dianalisis secara deskriptif.

\section{HASIL dan PEMBAHASAN}

\section{Morfologi Batang}

Tomat gunung memiliki bentuk batang bulat, warna hijau kecoklatan, beruas-ruas dan setiap buku memiliki cabang dengan permukaan kasar serta berbulu (Lampiran 1). Batang ratarata berdiameter $1,044 \mathrm{~cm}$, dengan kisaran diameter antara 0,922-1,240 cm. Rata-rata jumlah cabang yang terbentuk 17 cabang, dengan kisaran 12-22 cabang.

Dari hasil pengamatan juga terlihat bahwa semakin tinggi batang jumlah cabang yang dihasilkan lebih sedikit, sedangkan semakin rendah batang jumlah cabang yang dihasilkan semakin banyak. Kusandriyani et al., (2005) menyatakan bahwa variasi jumlah cabang pada tomat disebabkan oleh sifat genetik yang dibawa. Wartapa et al. (2009), menyatakan bahwa, cabang tanaman yang sedikit menyebabkan mutu buah dan benih meningkat.

Menurut Tjitrosoepomo (2007), tipe percabangan tomat merupakan percabangan simpodial, yaitu batang pokoknya sulit ditemukan karena dalam perkembangan selanjutnya, pertumbuhannya kalah cepat dibandingkan dengan cabang-cabangnya. Hal ini telihat seperti pada Gambar 3, yaitu ukuran batang pokok dengan cabangnya hampir sama sehingga batang pokoknya sulit untuk ditentukan.

Dari hasil pengamatan juga diperoleh bahwa pada setiap cabang yang terbentuk selalu diakhiri dengan bunga di ujungnya, dimana dan se- 
lanjutnya akan membentuk buah. Pada tipe determinate, pertumbuhan tanaman dimulai oleh organ vegetatif, kemudian dari pucuk tanaman muncul organ generatif yang akan menghasilkan buah. Setelah dua atau tiga kali selang-seling pertumbuhan vegetatif dan generatif, tanaman akan mati (Knott dan Deanon 1967).

\section{Morfologi Daun}

Berdasarkan hasil pengamatan pada 10 sampel diperoleh warna daun hijau tua, permukaan daunnya kasar dan berbulu, tepi daun dengan toreh berlekuk dan memiliki bentuk daun memanjang, ujung daunnya runcing, dan pangkal daunnya tumpul (Gambar 2).

Jumlah daun tiap tanaman berkisar 138 helai. Setiap tanaman menghasikan banyak daun yang tidak sama, hal ini dipengaruhi oleh faktor lingkungan dan genetik masing-masing tanaman (Subhan 1989; Sutapradja dan Sumarni
1996). Panjang anak daunnya rata-rata $5,3 \mathrm{~cm}$ dan lebarnya $2,2 \mathrm{~cm}$.

Daun termasuk daun majemuk menyirip dengan jumlah anak daun yang gasal, yaitu daun majemuk yang anak daunnya terdapat di kanan kiri ibu tangkai daun dan terdapat satu anak daun menutupi ujung ibu tangkainya (Tjitrosoepomo, 2005)

\section{Morfologi Bunga}

Berdasarkan Tabel 1 terlihat bahwa bunga tomat gunung memiliki panjang mahkota rata-rata $1,10 \mathrm{~cm}$, dan lebarnya $0,37 \mathrm{~cm}$. Panjang kelopak rata-rata $0,69 \mathrm{~cm}$ dan lebarnya $0,12 \mathrm{~cm}$. Benang sari berjumlah 5 , saling berlekatan dengan panjang rata-rata $0,68 \mathrm{~cm}$. Putiknya berjumlah 1 dengan panjang rata-rata $0,97 \mathrm{~cm}$. Setiap tanaman rata-rata menghasilkan bunga sebanyak 44 tandan dan pada setiap tandan rata-rata dihasilkan 6 bunga.

Tabel 1. Variasi Morfologi Bunga

\begin{tabular}{cccccccccc}
\hline No & $\begin{array}{c}\text { No } \\
\text { Tom } \\
\text { at }\end{array}$ & $\begin{array}{c}\text { Jumlah } \\
\text { Tandan } \\
\text { Bunga }\end{array}$ & $\begin{array}{c}\text { Jumlah Maks. } \\
\text { bunga tiap } \\
\text { tandan }\end{array}$ & $\begin{array}{c}\text { Panjang } \\
\text { Petala } \\
(\mathrm{cm})\end{array}$ & $\begin{array}{c}\text { Lebar } \\
\text { Petala } \\
(\mathrm{cm})\end{array}$ & $\begin{array}{c}\text { Panjang } \\
\text { Sepala } \\
(\mathrm{cm})\end{array}$ & $\begin{array}{c}\text { Lebar } \\
\text { Sepala } \\
(\mathrm{cm})\end{array}$ & $\begin{array}{c}\text { Panjang } \\
\text { Putik } \\
(\mathrm{cm})\end{array}$ & $\begin{array}{c}\text { Panjang } \\
\text { Stamen } \\
(\mathrm{cm})\end{array}$ \\
\hline 1 & 2 & 43 & $6-8$ & 1,10 & 0,30 & 0,60 & 0,12 & 0,90 & 0,70 \\
2 & 6 & 41 & $5-6$ & 1,10 & 0,50 & 0,70 & 0,15 & 0,90 & 0,70 \\
3 & 8 & 46 & $5-7$ & 1,50 & 0,40 & 0,90 & 0,10 & 1,00 & 0,70 \\
4 & 9 & 56 & $5-6$ & 1,10 & 0,40 & 0,70 & 0,10 & 1,10 & 0,70 \\
5 & 18 & 49 & $5-7$ & 1,10 & 0,40 & 0,60 & 0,10 & 0,90 & 0,60 \\
6 & 23 & 41 & $5-7$ & 1,10 & 0,40 & 0,70 & 0,10 & 1,10 & 0,70 \\
7 & 36 & 43 & $6-8$ & 1,00 & 0,40 & 0,70 & 0,10 & 0,90 & 0,70 \\
8 & 40 & 35 & $7-9$ & 1,10 & 0,40 & 0,65 & 0,10 & 1,10 & 0,75 \\
9 & 41 & 49 & $5-7$ & 0,80 & 0,30 & 0,60 & 0,10 & 0,80 & 0,60 \\
10 & 47 & 38 & $6-8$ & 1,10 & 0,35 & 0,80 & 0,10 & 1,10 & 0,70 \\
\hline Rata-rata & 44 & 6 & 1,10 & 0,37 & 0,69 & 0,12 & 0,97 & 0,68 \\
\hline
\end{tabular}

Bunga tomat gunung ini termasuk bunga majemuk, berbentuk bintang, zigomorf. Menurut Kurniasih (2011), pada umumnya berbagai varietas tomat memiliki jumlah daun mahkota dan daun kelopaknya sebanyak 5 helai. Pada tomat keriting, daun mahkota dan daun kelopaknya mencapai 10 helai, tomat permata mencapai 6 helai, sedangkan jumlah daun mahkota dan daun kelopak tomat gunung sama seperti tomat pada umumnya, yaitu berjumlah 5 helai. Daun mahkota berwarna kuning dan saling berlekatan sedangkan daun kelopak berwarna hijau tua dan saling berlepasan (Gambar 3, lampiran 1).

\section{Morfologi Buah}

Bentuk tomat juga mempengaruhi ukuran diameter dan panjang buahnya. Berdasarkan Tabel 2, secara keseluruhan, ukuran diameter tomat gunung hasil pengamatan yang terkecil berukuran 1,835 cm dengan panjang 1,977 cm sedangkan, ukuran diameter terbesar mencapai $3,444 \mathrm{~cm}$ dan panjangnya mencapai $3,069 \mathrm{~cm}$. Berat sebutir tomat gunung paling ringan mencapai $4,1 \mathrm{~g}$ dan yang terberat mencapai $14,8 \mathrm{~g}$. Diameter buah lebih banyak dipengaruhi oleh sifat genetik tanaman walaupun pertumbuhan dan perkembangan daun dipengaruhi oleh lingkungan, antara lain intensitas cahaya, temperatur, dan ketersediaan unsur hara, terutama unsur N dan P (Subhan 1989; Sutapradja dan Sumarni 1996).

Satu tanaman tomat gunung menghasilkan buah rata-rata sebanyak 284 butir dengan berat total buah tomat rata-rata $2,333 \mathrm{~kg}$. Diameter rata-rata buah tomat gunung ini $2,419 \mathrm{~cm}$ dan panjangnya $2,428 \mathrm{~cm}$. Berat tomat rata-rata 8,22 $\mathrm{g} /$ butir dan 2,33 kg/tanaman. Ruang buah yang terbentuk sebanyak 2 hingga 6 ruang 
Tabel 2. Variasi Morfologi Buah Tomat Gunung

\begin{tabular}{|c|c|c|c|c|c|c|c|c|}
\hline No & $\begin{array}{c}\text { No } \\
\text { Tomat }\end{array}$ & Bentuk Buah & $\begin{array}{l}\text { Diameter } \\
(\mathrm{cm})\end{array}$ & $\begin{array}{l}\text { Panjang } \\
\text { (cm) }\end{array}$ & $\begin{array}{c}\text { Berat } \\
(1 \text { buah })(g)\end{array}$ & $\begin{array}{c}\text { Jumlah } \\
\text { Buah }\end{array}$ & $\begin{array}{c}\text { Berat } \\
\text { Total }(\mathrm{kg})\end{array}$ & $\begin{array}{l}\text { Jumlah } \\
\text { Ruang }\end{array}$ \\
\hline 1 & 2 & Bulat & 2,142 & 2,095 & 7,170 & 301 & 2,158 & 2 \\
\hline 2 & 6 & Bulat & 1,835 & 1,977 & 4,100 & 246 & 1,008 & 3 \\
\hline 4 & 9 & Bulat & 2,103 & 2,269 & 6,050 & 336 & 2,032 & 3 \\
\hline 5 & 18 & Bulat pipih & 3,444 & 3,069 & 14,800 & 294 & 4,351 & 6 \\
\hline 6 & 23 & Bulat pipih & 2,990 & 2,849 & 12,020 & 246 & 2,956 & 4 \\
\hline 9 & 41 & Bulat & 2,243 & 2,278 & 7,340 & 294 & 2,157 & 3 \\
\hline 10 & 47 & Bulat & 2,047 & 2,183 & 7,250 & 266 & 1,928 & 3 \\
\hline \multicolumn{3}{|c|}{ Rata-rata } & 2,419 & 2,428 & 8,22 & 284 & 2,332 & 3 \\
\hline
\end{tabular}

Buah tomat gunung yang muda memiliki warna bervariasi yaitu, hijau tua, hijau tua dibagian atas dan hijau muda dibagian bawah serta hijau keputihan. Sedangkan, warna buah tomat yang sudah tua memiliki warna yang sama yaitu merah cerah dan mengkilap (Gambar 4, Lampiran 1).

The International Board for Plant Genetic Resources (IBPGR, 1981) menjelaskan bahwa bentuk buah tomat terbagi ke dalam 7 tipe, yaitu bulat (round), bulat lonjong (high round), gepeng (slightly flattened), memanjang (lengthened), bentuk pear (pearshaped) bentuk plum (plumshaped), dan bentuk hati (hearthshaped). Hasil pengamatan memperlihatkan bahwa bentuk buah tomat gunung cukup bervariasi yaitu, ada yang bulat dengan permukaan rata dan halus, bulat lonjong dengan permukaan rata dan halus, dan bulat pipih dengan permukaan sedikit bergelombang dan halus.

\section{SIMPULAN}

Dari hasil penelitian dan pembahasan, maka dapat disimpulkan bahwa:

a. Batang tomat gunung berbentuk bulat, warna hijau kecoklatan, beruas-ruas, tipe pertumbuhan determinate dengan tinggi ratarata $85,7 \mathrm{~cm}$, percabangan simpodial dengan jumlah cabang rata-rata 17 dan permukaannya kasar serta berbulu.

b. Daun tomat gunug memiliki warna hijau tua, permukaannya kasar dan berbulu, tepinya dengan toreh berlekuk dan bentuk daun memanjang, ujung daunnya runcing, pangkal daunnya tumpul dan termasuk daun majemuk menyirip rata-rata jumlah daun tiap tanaman berkisar 138 helai. Sedangkan rata-rata panjang daunnya $5,3 \mathrm{~cm}$ dan lebarnya 2,2 cm.

c. Bunga tomat merupakan bunga majemuk, berbentuk bintang, zigomorf, petala kuning, dan sepala hijau tua. Jumlah tandan bunga bervariasi rata-rata 44 tandan per tanaman dan jumlah maksimal pada satu tandan rata-rata 6 bunga. d. Buah tomat yang dihasilkan per tanaman rata-rata 288 buah dan terdapat tiga tipe variasi bentuk buah yaitu, bulat, bulat lonjong, dan bulat pipih bergelombang. Berat buah rata-rata $8,22 \mathrm{~g}$. Ruang buah jumlahnya bervariasi antara 2-6 ruang.

\section{DAFTAR PUSTAKA}

Knott, J.E. and J.R. Deanon. 1967. Vegetables production in South Asia. University of The Phillipines College of Agricultural. College Los Banos, Leguna. Phillipines.

Kurniasih, E. 2011. Keanekaragaman Morfologi Buah Tomat (Lycopersicum esculentum Mill.) di Pasar Bandar Lampung. (Skripsi). Universitas Lampung. Bandar Lampung.

Kusandriyani, Y., Lutfi dan Gunawan. 2005. Karakterisasi dan Deskripsi Plasma Nutfah Tomat. Buletin Plasma Nutfah. 11 (2): 55-9.

Sastrapradja, S dan M.A Rifai. 1989. Mengenal Sumber Pangan Nabati dan Plasma Nutfahnya. Puslitbang Bioteknologi-LIPI. Bogor.

Smartt, J., and N.W. Simmonds. 1995. Evolution of Crop Plants. Longman Scientific \& Technical. London.

Stertz, S. C., A.P.D. Espírito Santo, C. Bona, and R.J.S.D Freitas,. 2005. Comparative Morphological Analysis of Cherry Tomato Fruits from Three Cropping Systems. Scientia Agricola. 62 (3): 296-8.

Subhan, 1989. Pengaruh Dosis dan Waktu Pemberian Pupuk Nitrogen Terhadap Pertumbuhan dan Hasil Bayam Cabut. Buletin Penelitian Hortikultura. 22 (3): 3140.

Suryana. 2009. Keanekaragaman Jenis Tumbuhan Paku Terestrial dan Epifit di Kawasan PLTP Kamojang Kab. Garut Jawa Barat. Jurnal Biotika. 7 (1): 20-6.

Sutapradja, H dan N. Sumarni. 1996. Pengaruh Dosis Pengapuran dan Kombinasi Pupuk N dan $\mathrm{P}$ terhadap Pertumbuhan dan Hasil Tomat. Jurnal Hortikultura 6 (3): 263-8. 
The International Board for Plant Genetic Resources (IBPGR). 1981. Genetic Resources of Tomatoes and Wild Relative. Food Agriculture Organization of the United Nations. Italy.

Tjitrosoepomo, G. 2005. Morfologi Tumbuhan. Gajah Mada University Press. Yogyakarta
Wartapa, A., E. Yoniar, dan Sukadi. 2009. Pengaturan Jumlah Cabang Utama dan Pen-jarangan Buah Terhadap Hasil dan Mutu Benih Tomat Varietas Kaliurang (Lycopersicum esculentum Mill.). Jurnal Ilmu-ilmu Pertanian. 5 (2): 150-163. 


\section{Lampiran 1. Morfologi Batang, Daun, Bunga, dan Buah Tomat Gunung}
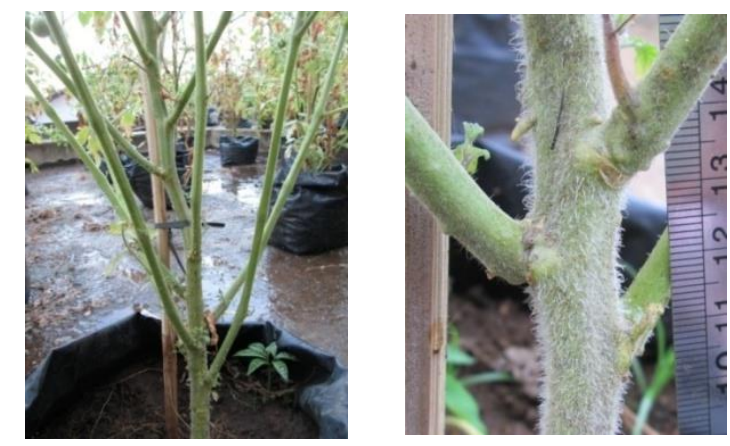

Gambar 1. Morfologi Batang Tomat Gunung

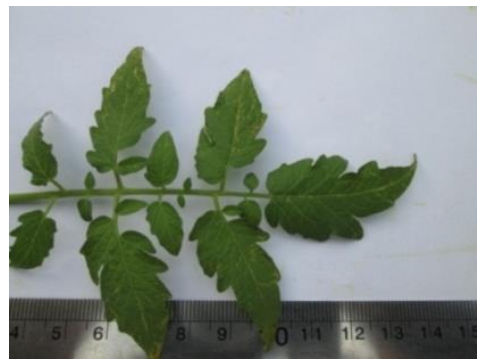

Gambar 2. Morfologi Daun Tomat Gunung

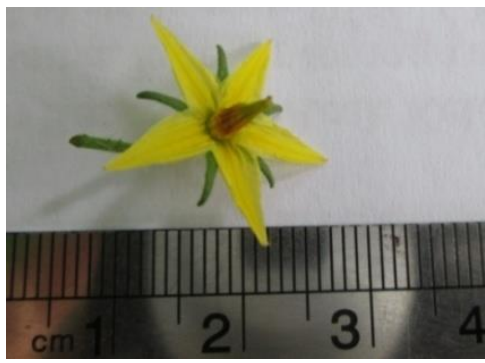

Gambar 3. Morfologi Bunga Tomat Gunung

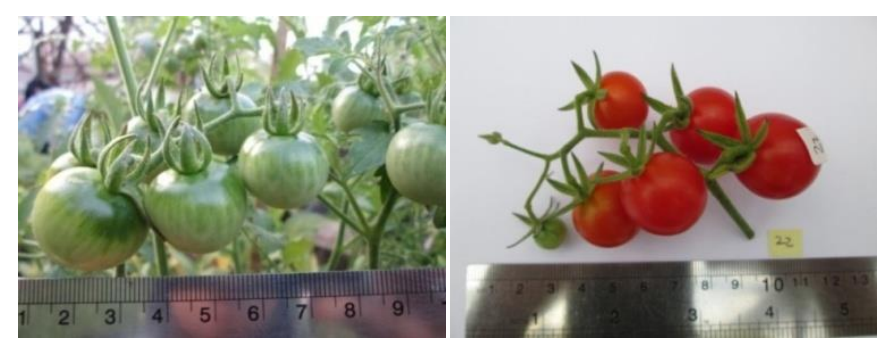

Gambar 4. Morfologi Buah Tomat Gunung Muda dan Tua
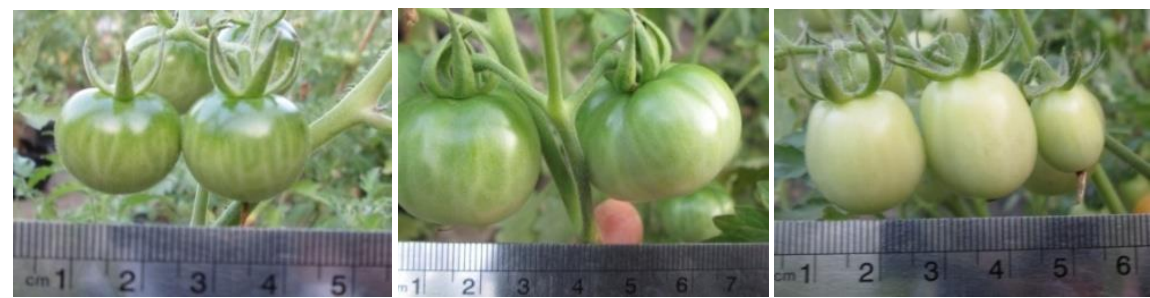

Gambar 5. Macam-macam Bentuk Buah Tomat Gunung

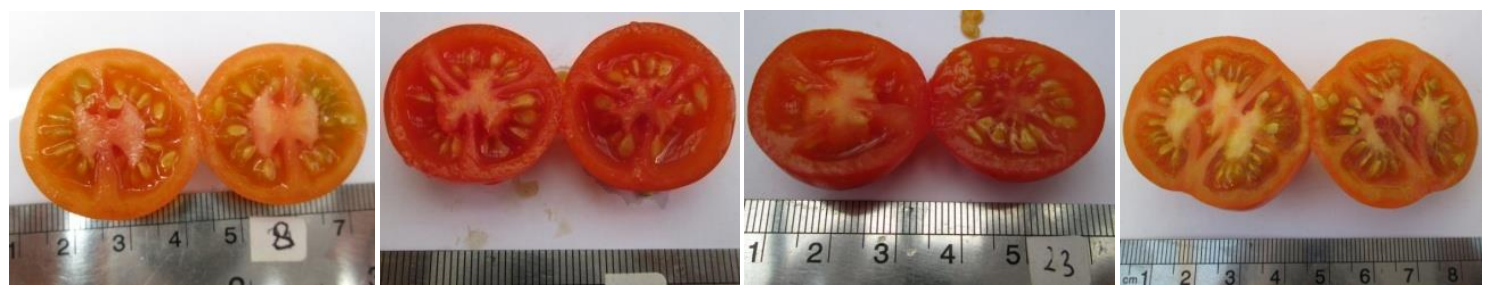

Gambar 6. Macam-macam Jumlah Ruang Buah pada Tomat Gunung 